\title{
Adoção da estratégia modular por empresas do setor automotivo e as implicações relativas à transferência de atividades no desenvolvimento de produto: um estudo de casos múltiplos
}

\author{
Adoption of the modular strategy for companies in the automotive \\ sector and the implications regarding the transfer of new product \\ development activities: a multiple case study
}

\author{
Evandro Prieto \\ Paulo Augusto Cauchick Miguel ${ }^{1}$
}

\begin{abstract}
Resumo: A modularidade aplicada ao desenvolvimento de novos produtos, acompanhada da terceirização das atividades de produção, tem sido uma estratégia adotada pelas montadoras automotivas. O desenvolvimento de produto no contexto da estratégia modular implica em uma redistribuição das atividades inerentes a este processo, baseando-se na decomposição e na divisão das tarefas entre as montadoras e seus fornecedores. Nesse contexto, este estudo investiga as implicações da estratégia modular no processo de capacitação e na transferência de atividades de desenvolvimento de produto entre os fornecedores de primeiro e segundo nível da cadeia de suprimentos automotiva. O trabalho é desenvolvido por meio de uma abordagem metodológica de múltiplos casos. As empresas investigadas foram posicionadas em níveis distintos de competências modulares - "embrionária", "em desenvolvimento" e "madura"-, de acordo com as evidências empíricas levantadas. Evidenciou-se uma relação entre o estágio de maturidade de competências e as principais atividades de desenvolvimento de produto.
\end{abstract}

Palavras-chave: Modularidade. Projeto modular. Desenvolvimento de produto. Setor automotivo.

\begin{abstract}
Modularity applied to new product development together with the externalisation of production has been a strategy adopted by automotive companies. New product development in the context of modular strategy implies a redistribution of inherent activities of production. This is based on a work division among assemblers and their suppliers. In this context, this study investigates the implications of modular strategies in the process of transferring value-added activities in new product development between first and second tier suppliers. The study is developed based on a multiple case study approach. The investigated companies were positioned in distinct levels of modular competencies ('embrionary', 'in development', and 'mature'), according to empirical evidence. A relationship between the stage of maturity and major new product development practices was identified.
\end{abstract}

Keywords: Modularity. Modular project. Product development. Automotive sector.

\section{Introdução}

As mudanças no cenário competitivo internacional, caracterizado pelo rápido desenvolvimento tecnológico, pela diminuição do ciclo de vida dos produtos e pela globalização de mercados, têm definido uma nova abordagem nos processos de projeto de desenvolvimento de produtos (PDP), produção e entrega de bens e serviços aos clientes do setor automotivo (HOEK; WEKEN, 1998; SHIMOKAWA, 2002). Humphrey e Schmitz (2001), Corswant e Fredriksson (2002), Sturgeon (2002), Doran (2003) e Morris, Donelly e Donelly (2004) compartilham a opinião de que no momento atual de novas tecnologias, como o comércio eletrônico e a globalização do fornecimento (global sourcing), as montadoras e seus parceiros estratégicos precisam melhorar o desempenho relativo à produção (entrega, confiabilidade, qualidade e custo) e ao desenvolvimento de produto (tempo, custo e taxa de inovação). Para que seja alcançada maior eficácia nestes requisitos-chave, mudanças na arquitetura das organizacões encontram-se em andamento e caminhando no sentido de um novo modelo de produção em rede modular. Neste sentido, o setor automotivo, liderado pelas montadoras, tem adotado a estratégia modular que se apresenta

Programa de Pós-Graduação em Engenharia de Produção, Escola Politécnica, Universidade de São Paulo - USP,

Av. Prof. Almeida Prado, ${ }^{\circ}$ 128, Trav. 2, $2^{\circ}$ andar, Cidade Universitária, CEP 05508-070, São Paulo, SP,

E-mails: evandroprieto@rocketmail.com.br; cauchick@usp.br

Recebido em 20/8/2008 — Aceito em 3/4/2011

Suporte financeiro: CNPq. 
compatível com a necessidade de aumentar a eficiência e a rentabilidade do negócio, por meio da integração de ações para reduzir custos e aumentar a produtividade, da redução de riscos de investimento via terceirização de atividades de produção e de projeto para os fornecedores (MARTIN; ISHII, 2000).

A implantação e a expansão do conceito da estratégia modular implicam na redistribuição das atividades entre todos os integrantes da cadeia de suprimentos que agregam valor ao produto final, o que também implica em uma nova configuração nas atividades de produção e projeto de desenvolvimento de produto - PDP (DORAN; ROOME, 2003). Esta nova configuração produtiva se dá em um processo de transferência de atividades, até então exercidas pelas montadoras, para os seus fornecedores, os quais assumem, total ou parcialmente, a produção e as atividades de projeto (STURGEON, 2002; DORAN, 2003). O processo de transferência de atividades de PDP entre os integrantes da cadeia de suprimentos é possível graças ao domínio de toda a arquitetura do projeto do veículo por parte da montadora, que controla e define as especificações de engenharia dos diferentes módulos que integram um produto com funcionalidade única (HENDERSON; CLARK, 1990).

Quanto maior o grau de maturidade de um fornecedor, maior a possibilidade de as montadoras realizarem transferência de atividades em áreas, como: pesquisa e desenvolvimento (P\&D); projeto para manufatura; compra de componentes; manufatura; testes, e embalagens (DORAN, 2004). Este processo de transferência de atividades aos fornecedores impulsiona a definição de um novo modelo de arquitetura organizacional modular e de produção em redes, no qual fornecedores estabelecem unidades locais em um sistema de condomínio industrial ou consórcio modular (STURGEON, 2002), sendo que sistemas híbridos podem ocorrer entre condomínio industrial e consórcio modular. Do ponto de vista da análise da cadeia automotiva, a montadora é cada vez mais explicitamente a orientadora das estratégias de todas as empresas a montante e, consequentemente, são as estratégias da montadora que definem a configuração do modelo produtivo a ser instalado.

Entende-se que as novas possibilidades de subcontratação de atividades de PDP com a contínua aquisição de competências modulares pelo fornecedor (adotando-se como base a proposta de DORAN, 2004) determinam tanto o processo de transferência como o grau de envolvimento nas atividades de PDP. Dado este contexto, neste estudo investigam-se as implicações da estratégia modular no processo de capacitação e na transferência de atividades de PDP entre os fornecedores de primeiro e segundo nível da cadeia de suprimentos automotiva.

\section{Referencial teórico}

Neste trabalho, a abrangência das atividades de PDP investigadas está delimitada às etapas da arquitetura de produto de concepção modular conforme proposta de Ulrich e Eppinger (1995) e às suas implicações estratégicas quanto à cadeia de suprimentos automotiva. $\mathrm{O}$ referencial teórico utilizado neste trabalho se atém aos tipos de arquitetura de projeto (integral e modular) e às implicações da opção pela estratégia modular (com foco nas tendências de terceirização de projetos) na gestão do PDP entre as montadoras e seus fornecedores.

\subsection{Concepção de arquitetura de produto}

A literatura aponta o emprego de duas estratégias de concepção de arquitetura nos PDP como alternativas para oferecer uma proposição de valor ao cliente: a arquitetura integral e a modular (NEPAL, 2005). Huang (2000) considera que um produto de arquitetura integral define que cada um de seus componentes desempenhe muitas funções por meio de relações físicas e/ou espaciais (volumétricas) muito próximas, ou o inverso - um componente desempenha uma única função e estabelece diversas relações com outros componentes, o que requer grande sincronização. O fato de o produto de arquitetura integral ser projetado para maximizar certa medida de desempenho sem a consideração de que seus elementos funcionais possam ser independentes entre seus diversos submódulos pode determinar que possíveis modificações em um de seus componentes ou característica requeiram reprojeto intensivo de todo o produto. Segundo Sanchez (2002), um produto deve apresentar uma proposição de valor por meio das suas funcionalidades e das possibilidades de interface entre os componentes de um módulo e deste com outros. Como observam Baldwin e Clark (1997), um produto de arquitetura modular é utilizado para construir produtos e módulos complexos, como no caso dos veículos, com base na definição de unidades padronizadas de maior funcionalidade que um projeto integral e que possibilita uma simplificação na sua desmontagem e remontagem. Em função do fato de que parte das montadoras adotam o conceito de PDP de arquitetura modular, a cadeia de suprimentos adquire, desenvolve e acumula conhecimento no que se refere a como integrar seus módulos e submódulos uns com os outros para a realização da montagem final do veículo.

O fundamento da terceirização, para que ocorra uma progressiva transferência de atividades, é apresentado por Yassine e Wissmann (2007), que verificaram que a decomposição dos módulos de um projeto modular permite o seu desenvolvimento de forma independente entre diversas equipes, internas ou externas à organização. A padronização das interfaces entre os módulos e as especificações das informações 
de projeto rigorosamente definidas e controladas pelas montadoras permitem a descentralização das atividades de projeto (off line), para que, em um momento posterior, ocorra a integração de cada módulo em uma arquitetura única do veículo. Uma das vantagens deste tipo de arquitetura é a possibilidade de ser aplicada em certa quantidade de modelos de veículos de uma só vez (FREDRIKSSON, 2002).

De acordo com Ulrich (1995), na maioria das vezes, um componente padronizado, como o de arquitetura modular, tem um custo mais baixo do que um componente projetado e construído para uso exclusivo em um só produto (arquitetura integral). Na verdade, um produto não pode ser classificado como estritamente modular ou integral; os produtos podem ser classificados relativamente a outros produtos de acordo com o seu grau de modularidade (ULRICH; EPPINGER, 1995). Quanto maior o grau de modularidade de um produto, maior o tempo necessário em sua fase inicial de desenvolvimento dos componentes, mas, ao longo do tempo, diminui tal demanda conforme as suas interações começam a ser mais bem definidas.

\subsubsection{Terceirização aplicada a projeto de produto}

A estratégia modular se constitui na combinação da modularidade aplicada ao PDP com a possibilidade da terceirização de suas atividades. Graziadio (2004) considera que modularidade significa produzir componentes de um produto ou processo complexo de modo independente, por empresas diferentes, para que depois outra empresa monte os sistemas formando o conjunto conforme previsto. Nesta abordagem, a terceirização é parte da modularidade - uma estratégia que faz a opção pela combinação da modularidade do produto e a terceirização de suas atividades de desenvolvimento. No entanto, cabe ressaltar que os módulos podem ser produzidos internamente tanto pela montadora como pelos seus fornecedores.

A terceirização das atividades de manufatura permite às montadoras dedicarem-se ao que mais agrega valor - projeto de plataforma, conceito do veículo e motor (STURGEON, 2002; GRAZIADIO, 2004). A terceirização de projeto dos componentes significa transferir atividades de projeto para os fornecedores. Para mensurar essa participação, Clark e Fujimoto (1991) e Monczka (2000) analisam os tipos de produtos de cada fornecedor, e sugerem 4 categorias: i) componentes de propriedade dos fornecedores (componentes padronizados, cujo desenvolvimento e fabricação são realizados integralmente pelos fornecedores e vendidos a diferentes clientes, implicando em pequeno domínio sobre níveis inferiores da cadeia produtiva); ii) componentes com controle detalhado de especificação (componentes desenvolvidos pelos clientes encomendados aos fornecedores em detalhes - os clientes fornecem especificações, desenhos e em certos casos até o equipamento ou ferramental necessário para sua produção); iii) componentes grey box: as especificações do produto são definidas pelo cliente em conjunto com o fornecedor e o domínio dos detalhes de engenharia é compartilhado; e iv) componentes black box: projeto desenvolvido pelo fornecedor a partir do que a montadora define como atributos de produto, desempenho, estilo, preço, etc. $\mathrm{O}$ fornecedor detalha o projeto (esboços, protótipos, testes) e a montadora apenas acompanha o processo.

\subsection{Tendências de abordagem modular na cadeia de suprimentos}

As estratégias das montadoras e dos sistemistas (fornecedores que trabalham com a interação de sistemas, em geral, modulares) podem influenciar as decisões de localização de capacidade produtiva especificamente para os fornecedores de componentes que estão no segundo nível na cadeia de suprimentos. A modularidade associada à terceirização pode ser considerada como uma decisão que está mais relacionada à gestão do negócio do que com a produção. É uma forma de redução do volume de investimentos e riscos associados à determinada atividade industrial, para a montadora dedicar-se ao que mais agrega valor, como projeto de plataforma, conceito do veículo, motor (GRAZIADIO, 2004). Cada uma das montadoras tem uma lista de atividades não centrais, e, portanto, passíveis de terceirização.

Nas decisões de capacidade produtiva, de acordo com Calabrese (2001), as empresas automotivas americanas e europeias estão implementando o modelo japonês de relacionamento com seus fornecedores nos moldes da estratégia modular, na qual: a) a produção interna representa menos de $30 \%$ do valor total do produto. A maioria dos fabricantes japoneses de automóveis mantém o controle da produção dos motores, powertrain e chassis; b) o número de fornecedores diretos está limitado a poucas centenas, muitos dos quais são responsáveis pela montagem de módulos; c) utilizando-se do contato direto com os fornecedores estratégicos (primeiro nível), a definição da estrutura da cadeia em níveis coopera para o controle dos fornecedores de segundo nível; d) contratos de longo prazo permitem o planejamento da redução dos custos e a estabilização dos lucros; e e) os componentes desenvolvidos pelos fornecedores representam grande parte do valor total do projeto (mais de 70\%).

Em paralelo a este processo de mudanças nas relações entre fornecedores e montadoras, o produto final (veículo) é simplificado, em grande parte, pela redução no número de linhas de produto por modelo 
e pela utilização de módulos. A soma destes fatores causa uma redução no número de fornecedores diretos e, potencialmente, poucas firmas por unidade de produto (COLLINS; BECHLER; PIRES, 1997). Os fornecedores que participam no consórcio modular da Volkswagen em Resende, no Rio de Janeiro (atual MAN Latin America), estão plenamente comprometidos com todo o processo de integração logística, just in time e PDP.

Alguns casos de produção modular são mencionados na literatura. Entre eles, estão o condomínio industrial utilizado na Skoda (República Tcheca) e o consórcio modular na Volkswagen em Resende-RJ, que apresentam níveis distintos de terceirização pelas montadoras. Na fábrica de caminhões da Volkswagen, o consórcio modular foi resultado de um investimento conjunto de 7 fornecedores denominados "modulistas" (antes da inauguração da planta, a Volkswagen gerenciava 400 fornecedores), que montam diretamente na fábrica os 7 módulos seguintes (SALERNO; DIAS, 1999). A fábrica da Skoda que produz o modelo Octavia apresenta-se em um momento de transição de um sistema de condomínio industrial para o consórcio modular. Neste caso, existem 3 fornecedores de sistemas modulares com áreas exclusivas de produção e responsáveis somente pela sua montagem. Os 3 fornecedores realizavam montagem compartilhada de módulos do front end e do painel diretamente na linha de montagem. A montagem do restante do veículo fica sob a responsabilidade da Skoda (COLLINS; BECHLER; PIRES, 1997).

Neste contexto, os fornecedores modulares podem se beneficiar com o aumento das responsabilidades, o maior envolvimento nos processos de PDP e a possibilidade de criação de atividades de maior valor adicionado (DORAN, 2004).

\subsection{Integrantes da cadeia de suprimentos segundo o grau de competência modular}

Neste trabalho, o posicionamento relativo dos fornecedores na cadeia de suprimentos é considerado conforme os seus níveis de competências modulares e é classificado em 3 categorias (primeiro, segundo e terceiro níveis). Conforme demonstrado na Figura 1, um dos modelos de fornecimento utilizados com maior intensidade no momento pelo setor automotivo, o condomínio industrial, tende a evoluir no sentido das parcerias diretas das montadoras com os fornecedores de primeiro nível.

Esta tendência de configuração pressupõe que o fornecedor de primeiro nível realize a montagem de módulos diretamente na planta da montadora e os fornecedores de segundo e terceiro níveis fornecendo componentes e peças.

Considerando-se a classificação do nível de capacitação tecnológica dos fornecedores como parâmetro de posicionamento na cadeia de suprimentos, Figueiredo (2003) propõe dois tipos de capacidade tecnológica: uma necessária para operar o sistema de produção existente (capacitação operacional rotineira) e aquela necessária para mudar (capacitação tecnológica inovadora). Com base nas análises de Camuffo (2000), a respeito das competências tecnológicas do setor automotivo, as competências modulares de um fornecedor considerado estratégico (de primeiro nível), que tem capacidades tecnológicas inovadoras bem desenvolvidas, devem possibilitar a prestação de serviços completos por meio do suprimento e da montagem de módulos e submódulos em larga escala. Os fornecedores de primeiro nível em um ambiente modular são provavelmente aqueles que desenvolveram - ou estão em processo de

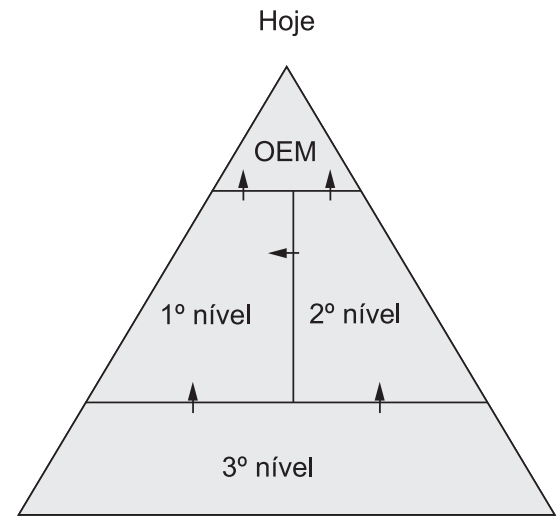

- Primeiro e segundo nível não estão claramente definidos

- De forma geral, ambos, primeiro e segundo nível possuem relação direta com a montadora

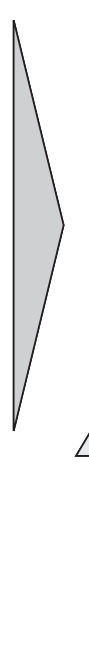

Tendência futura

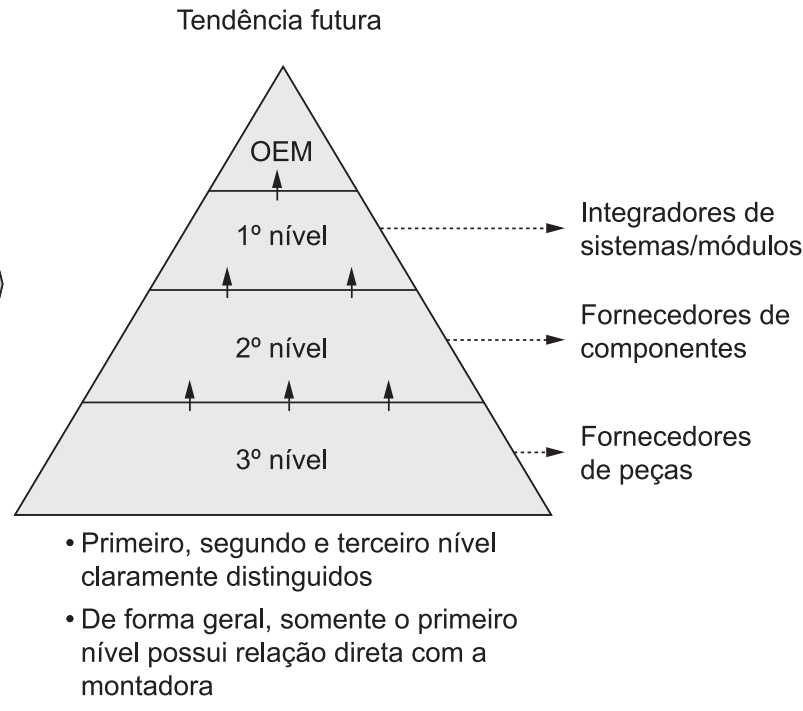

Figura 1. Estrutura de fornecimento da cadeia automotiva (adaptado de JÜRGENS, 2004). 
desenvolver - as competências que são críticas para a entrega de soluções modulares (DORAN, 2004).

Frequentemente, os fornecedores de primeiro nível possuem uma ampla variedade de capacitações tecnológicas avançadas, incluindo pesquisa e desenvolvimento $(\mathrm{P} \& \mathrm{D})$, que proporcionam um fluxo de produção constante para os módulos de montagem automotivo, fixam seus componentes diretamente na planta dos seus clientes (montadoras); dessa forma, estão capacitados a gerenciar as condições de qualidade e entrega dos seus produtos e dos fornecedores dos outros níveis na cadeia de suprimentos. Morris, Donelly e Donelly (2004) citam como exemplo as seguintes empresas, que estão adequadas às características descritas: Delphi, Lear, Faurecia, Plastic Omnium e Valeo. Como forma de adicionar maior valor aos produtos e serviços, grande parte destes fornecedores estratégicos estão assumindo novas funções (entrega sincronizada, co-design e suporte global) e, progressivamente, se capacitando e se adequando ao conceito de fornecimento modular, segundo o qual assumem a responsabilidade pela montagem das peças ou submódulos em um único módulo que constitui um sistema (COLLINS; BECHLER; PIRES, 1997).

Os fornecedores do segundo nível da cadeia de suprimentos tendem a se posicionar em um patamar inferior de comprometimento e contribuição indireta com as montadoras, em razão das suas limitações no nível de capacitação tecnológica, com ênfase nas atividades rotineiras e nos aspectos de desenvolvimento, produção e fornecimento de componentes ou mesmo módulos simples (STURGEON, 2002). As empresas no terceiro nível da cadeia de suprimentos, que não são contempladas neste estudo, são fornecedores de produtos do tipo "commodities", isto é, componentes em geral simples para as empresas de primeiro e segundo níveis.

O processo de transferência das atividades pelas montadoras, em primeira instância, aos fornecedores estratégicos também acarreta o subsequente repasse em "efeito cascata" aos outros fornecedores de componentes e submódulos da cadeia (DORAN, 2004). Em função destes fatores mencionados, as implicações na adoção da modularidade são diversas. Entre outros aspectos, está em andamento um processo de capacitação dos integrantes da cadeia de suprimentos e consequente redistribuição do valor, que objetiva aumentar a maturidade nas relações de fornecimento.

\section{Avaliação da maturidade modular dos fornecedores}

Doran (2004) propõe uma tipologia para identificar a progressividade de competências modulares, que analisa qual o grau de maturidade modular do fornecedor para agregar soluções modulares ao produto final das montadoras de veículos. $\mathrm{Ou}$ seja, o autor define alguns fatores fundamentais para medir o grau de maturidade modular dos fornecedores que podem colaborar para a consolidação de uma arquitetura modular no setor automotivo. A proposta do autor supracitado é identificar o grau de maturidade modular e então classificar as empresas fornecedoras de soluções modulares em 3 estágios: "embrionárias", "em desenvolvimento" e "maduras". A proposta do Quadro 1 é que sejam analisadas as seguintes competências, denominadas de fatores "ganhadores de pedidos": 1) recursos-chave; 2) estrutura para o fornecimento de produtos e serviços; 3) relacionamentos interorganizacionais; 4) definição de estratégias nas operações produtivas; 5) posicionamento estratégico de acordo com as demandas de desenvolvimento de produto modular; 6) diferenciais competitivos (principais fatores que definem a progressividade de competências modulares); e 7) potencial de transferência de atividades (resultado de todos os fatores anteriormente analisados - avaliação da maturidade nas competências modulares).

Conforme as evidências de Doran (2004), o grau de maturidade do fornecedor em relação aos requisitos estabelecidos pelas montadoras define as possibilidades de transferência de atividades em PDP nas seguintes competências tecnológicas: $\mathrm{P} \& \mathrm{D}$, projeto para manufatura, compra de componentes, manufatura, testes e embalagens. Em essência, a maturidade de um fornecedor modular é medida por seu potencial para receber atividades de uma montadora. $\mathrm{O}$ processo de identificação de quais atividades podem ser transferidas ou empurradas (pushed up) para a cadeia de suprimentos tem o objetivo de possibilitar às montadoras e aos fornecedores de primeiro nível centrar-se, prioritariamente, nas atividades criadoras de valor que são consideradas como principais para o processo de produção modular (DORAN, 2004).

Com o objetivo de ampliar a proposta de Doran (2004), apresentada no Quadro 1, outras publicações também foram consideradas. Uma síntese das referências identificadas sobre estes autores é apresentada no Quadro 2.

Outro aspecto identificado no presente trabalho corresponde aos tipos de atividades em que os fornecedores estão envolvidos, identificadas na literatura (CLARK; FUJIMOTO, 1991; HANDFIELD et al., 2000; STURGEON, 2002; DORAN, 2002; GRAZIADIO, 2004; ROZENFELD, 2005): P\&D, PDP e manufatura, compra de componentes, testes e embalagens.

As atividades de PDP e de manufatura são organizadas no Quadro 3 em 3 categorias: a) as atividades decorrentes da participação dos fornecedores nos estágios iniciais de definições da estratégia do produto; b) envolvimento com o desenvolvimento e 
Quadro 1. Progressividade de competências modulares (adaptado de DORAN, 2004).

\begin{tabular}{|ll}
\hline \multicolumn{1}{|c}{ Embrionárias } & \multicolumn{1}{c}{ Em desenvolvimento } \\
\hline Recursos-chave & \\
Baixa capacidade tecnológica & Capacitação tecnológica e financeira \\
Habilitado para o fornecimento & Operações pontuais fora do país de \\
de peças e de pequenos conjuntos & origem \\
de concepção modular & Significativa orientação para P\&D em \\
Não possui identidade de marca & projetos de co-design \\
& Habilitação para fornecer módulo \\
& Desenvolvendo marca própria
\end{tabular}

\section{Estrutura para o fornecimento de produtos e serviços}

Limitado às diretrizes impostas pelos clientes

Pouco posicionado para

acomodar mudanças de produto

integral para modular

\section{Relacionamentos interorganizacionais}

As montadoras definem

os termos e condições, e

impõem penalidades pelo não

cumprimento

Componentes estão sujeitos a

inspeção das montadoras

Foco em diversos setores

\section{Operações produtivas}

Operações em pequena escala

Podem atender outros setores

além do automotivo

Pouca flexibilidade operacional

\section{Posicionamento estratégico}

É um agente reativo e não tem visão de longo prazo frente às mudanças que estão ocorrendo no setor

\section{Diferenciais competitivos}

Não possui fatores considerados como ganhadores de pedido

\footnotetext{
Resultado: Potencial de transfer

Limitada pela baixa capacidade

de criação de valor
}

Desenvolvendo a capacidade de gestão do segundo nível

Presente em muitas das regiões-chave de produção, mas com presença

limitada na cadeia global

\begin{abstract}
Desfrutam de confiabilidade quanto aos contratos estabelecidos

Proporcionam qualidade assegurada aos componentes em um sistema JIT Foco em um único setor
\end{abstract}

Alta capacitação tecnológica e financeira

Grande orientação para P\&D em projetos de co-design

Habilitação para fornecer módulo e, em alguns casos, realiza a sua venda Marca própria ou ampla linha de produtos

Deve controlar elementos-chave do segundo nível, particularmente no âmbito em que o fornecedor está desenvolvendo sua posição de fornecedor modular

Desfrutam de confiabilidade quanto aos contratos estabelecidos Qualidade assegurada aos módulos em um sistema JIT ou de forma sincronizada

Foco em um único setor
Operações de média capacidade Foco exclusivo no setor automotivo Flexibilidade nas operações
Operações de alta capacidade e presença global Foco exclusivo no setor automotivo Flexibilidade nas operações e possibilidade de alimentação direta na linha da montadora

É um agente pró-ativo que está atento às mudanças-chave que ocorrem no setor e está posicionado para fornecer soluções modulares

Tem foco bem definido frente às mudanças que ocorrem no setor e tem realizado investimentos necessários para se posicionar como principal agente dentro de um ambiente modular

Provavelmente, define-se por: presença global e habilidade de prover soluções modulares em uma base sincronizada, e desenvolvendo capacidades de gestão do segundo nível

Provavelmente, define-se por: presença global, competências bem desenvolvidas em P\&D, tem uma linha de produtos de marca e plena capacidade de gestão do segundo nível

Alto potencial 
Quadro 2. Determinantes de competências modulares e atividades de PDP - empresas com maturidade modular.

\begin{tabular}{|c|c|}
\hline \multicolumn{2}{|l|}{ Recursos-chave } \\
\hline $\begin{array}{l}\text { Capacitação tecnológica como fator determinante } \\
\text { para as transferências de atividades }\end{array}$ & Doran (2003) \\
\hline Acumulação de competências e repartição no SCM & Becker e Zirpoli (2003) e Graziadio e Zilbovicius (2003) \\
\hline Presença global & $\begin{array}{l}\text { Collins, Bechler e Pires (1997); Sturgeon (2002); Svensson } \\
\text { (2004) e Doran (2003 e 2004) }\end{array}$ \\
\hline Especialização em P\&D & Camuffo (2000); Clark e Fujimoto (1991) e Sturgeon (2002) \\
\hline Produto de marca & Sturgeon (2002) e Doran (2004) \\
\hline \multicolumn{2}{|l|}{ Estrutura para o fornecimento de produtos e serviços } \\
\hline Supply Chain Management (SCM) & $\begin{array}{l}\text { Collins, Bechler e Pires (1997); Sturgeon (2002); Doran } \\
(2002,2003,2004) \text {; Svensson (2004) }\end{array}$ \\
\hline $\begin{array}{l}\text { Co-design segundo o nível de conhecimento da } \\
\text { arquitetura do produto }\end{array}$ & Becker e Zirpoli (2003) e Graziadio e Zilbovicius (2003) \\
\hline \multicolumn{2}{|l|}{ Relacionamentos interorganizacionais } \\
\hline Contratos com os clientes & Doran (2002) \\
\hline $\begin{array}{l}\text { Forte cultura da qualidade, atendimento às } \\
\text { especificações técnicas e entrega dos produtos }\end{array}$ & $\begin{array}{l}\text { Collins, Bechler e Pires (1997); Hoek; Weken (1998); } \\
\text { Camuffo (2000); Handfield et al. (2000); Sturgeon (2002) e } \\
\text { Doran (2003) }\end{array}$ \\
\hline \multicolumn{2}{|l|}{ Operações produtivas desenvolvimento de projetos } \\
\hline Flexibilidade operacional e de projeto & Doran (2004) \\
\hline Capacidade modular (projeto funcional e forma) & Henderson e Clark (1990) e Ulrich e Eppinger (1995) \\
\hline \multicolumn{2}{|c|}{ Resultado: Potencial de transferência de atividades/know how } \\
\hline $\begin{array}{l}\text { Processo de transferência de atividades e as } \\
\text { implicações em mudanças no SCM }\end{array}$ & $\begin{array}{l}\text { Henderson e Clark (1990); Sturgeon (2002); Doran (2003, } \\
\text { 2004) e Graziadio (2004) }\end{array}$ \\
\hline
\end{tabular}

Quadro 3. Tipos de atividades de PDP e manufatura para empresas com maturidade modular.

\section{A) Definições da estratégia do produto \\ 1 - Avaliação/desenvolvimento tecnológico do produto (P\&D) \\ 2 - Auxílio na definição da estratégia do produto (PDP e manufatura)}

\section{B) Envolvimento com o desenvolvimento e definição das especificações}

3 - Definição de requisitos do produto/arquitetura modular (testes no DP)

4 - Definição de requisitos da peça/componente modular

5 - Participação no PDP (projeto funcional e forma)

6 - Sugestão de alterações no produto (PDP e manufatura)

7 - Desenvolvimento da peça (DP)

8 - Auxílio nos testes do produto (estrutura interna para realização de testes)

C) Envolvimento com a preparação da produção e serviços ao cliente

9 - Projeto de manufatura

10 - Participa de testes de manufatura

11 - Compra de componentes

12 - Testes e embalagens

13 - Comercializa o produto (marca e domínio dos canais de distribuição)

14 - Produz a peça (terceirização da manufatura)

15 - Vende a peça por catálogo (marca) 
a definição das especificações, e c) desenvolvimento com a preparação da produção e serviços ao cliente.

A intensidade do envolvimento dos fornecedores nas atividades de PDP e manufatura é reflexo da estratégia de relacionamento que as montadoras definem com seus fornecedores de primeiro nível e do grau de contribuição que podem proporcionar para a "customização" dos veículos (HUMPHREY, 1999). A participação dos fornecedores desde o início das definições da estratégia do produto proporciona a possibilidade do estabelecimento de relacionamentos duradouros e a contribuição com grau elevado de "customização" dos veículos.

\section{Abordagem metodológica de pesquisa}

Como já delineado, o objetivo geral do presente trabalho é identificar, descrever e analisar as implicações da estratégia modular (modularidade e externalização aplicada às atividades de desenvolvimento de produto) nos processos de capacitação e as potencialidades de transferência de atividades de desenvolvimento de produto entre os fornecedores da cadeia automotiva. Para atender este objetivo geral, as seguintes questões de pesquisa foram consideradas: 1) Quais são os determinantes de competências que podem influenciar o potencial de transferência de atividades de DP entre os integrantes da cadeia automotiva? 2) Quais são as atividades em desenvolvimento de produto características dos fornecedores modulares de nível 1 e 2 da cadeia de suprimentos e sua relação com o respectivo estágio de progressividade de competências em que cada um está posicionado?

Classifica-se este estudo como de natureza exploratória, por considerar-se que a modularidade, no contexto de desenvolvimento de produto, é um tema ainda não consolidado na literatura. Um estudo exploratório se justifica quando se investiga um fenômeno contemporâneo (no caso, a modularidade) em um contexto real, nas atividades na cadeia automotiva (YIN, 2005). Trata-se ainda de uma pesquisa cuja natureza dos dados é qualitativa, adotando como abordagem de pesquisa o estudo de casos múltiplos. Seguindo a recomendação de Eisenhardt (1989), 4 a 10 estudos de casos são suficientes para um estudo com essas características.

As etapas desta pesquisa e atividades foram pré-definidas segundo Yin (2005): i) definição da estrutura conceitual-teórica: mapeamento da literatura para a definição preliminar das questões da pesquisa; ii) planejamento dos casos: seleção de unidade(s) de análise e contato(s), escolha dos meios para coleta e análise dos dados, e desenvolvimento do protocolo para a coleta dos dados; iii) condução do trabalho de campo: coleta (contato e registro dos dados) e análise dos dados (produção de uma narrativa, redução de dados e identificação de causalidade), e iv) elaboração do relatório de pesquisa: análise dos dados provenientes dos casos e posterior comparação com a literatura.

O Tabela 1 apresenta uma síntese das principais características das unidades de análise do trabalho.

Para a condução do trabalho de campo, foram selecionadas empresas com perfil de fornecedores estratégicos de primeiro e segundo níveis da cadeia de suprimentos automotiva e participantes no PDP em projetos modulares. Para a identificação de empresas com o perfil desejado, foi realizada uma consulta junto aos executivos do Sindipeças e, assim, foram selecionadas empresas participantes de processos de desenvolvimento de produtos modulares, que concordaram em participar do estudo.

Como recomenda Eisenhardt (1989), o uso de múltiplas fontes de dados e a iteração com a literatura possibilita o alcance de uma maior validade construtiva da pesquisa. $\mathrm{O}$ cruzamento das informações advindas das diversas fontes permitiu maior consistência na análise individual dos casos. Posteriormente, é feita uma análise cruzada dos dados.

\subsection{Delineamento metodológico}

Primeiramente, foi identificada a tipologia de competências modulares (baseada no Quadro 1); depois, definiu-se o referencial de determinantes das competências modulares e atividades de PDP para empresas com maturidade modular (com base no Quadro 2) e, na sequência, foram identificados os tipos de atividades no PDP e na manufatura para empresas com maturidade modular (baseado no referencial do Quadro 3). Após essa fase, com o objetivo de responder às questões propostas para este estudo, foi realizada a análise individual dos casos de acordo com as competências modulares identificadas, segundo a tipologia proposta por Doran (2004), no Quadro 1. As empresas também foram classificadas segundo o grau de envolvimento nas atividades de PDP e manufatura. Tais resultados são mostrados após uma síntese individual dos casos.

\subsection{Descrição das unidades de análise}

Dentre as quatro empresas selecionadas e investigadas, quatro unidades estão localizadas na Grande São Paulo e uma unidade, na região de Sorocaba; as empresas estão identificadas como Alfa, Beta, Gama e Ômega por motivos de confidencialidade. As empresas estão inseridas no contexto modular e possuem tradição no mercado automotivo brasileiro, pois operam por mais de quatro décadas no setor e possuem um histórico de competitividade frente às mudanças nos padrões tecnológicos e de gestão organizacional. 
Tabela 1. Características principais das empresas selecionadas.

\begin{tabular}{|c|c|c|c|c|}
\hline $\begin{array}{c}\text { Principais } \\
\text { Características }\end{array}$ & Alfa & Beta & Gama & $\begin{array}{c}\hat{O} \operatorname{mega}(1,2) \\
(1)\end{array}$ \\
\hline Início das operações & 1957 & 1965 & 1945 & 1967 \\
\hline $\mathrm{N}^{\circ}$ funcionários & 400 & 1200 & 2800 & 4000 \\
\hline $\begin{array}{l}\text { Faturamento } 2006 \\
\text { (MUS\$) }\end{array}$ & 20 & 125 & 300 & 450 \\
\hline $\begin{array}{l}\text { Segmentos de } \\
\text { mercado }\end{array}$ & Indústria & $\begin{array}{c}\text { Indústria e } \\
\text { concessionárias }\end{array}$ & $\begin{array}{l}\text { Indústria, varejo e } \\
\text { concessionárias }\end{array}$ & $\begin{array}{l}\text { Indústria e rede de } \\
\text { concessionárias }\end{array}$ \\
\hline Linha de produtos & $\begin{array}{c}\text { Componentes } \\
\text { avulsos e conjuntos } \\
\text { estampados }\end{array}$ & $\begin{array}{l}\text { Subsistemas de } \\
\text { transmissões e } \\
\text { direção }\end{array}$ & $\begin{array}{c}\text { Peças avulsas e } \\
\text { subsistemas de } \\
\text { vedação e condução }\end{array}$ & $\begin{array}{c}\text { Sistemas de } \\
\text { transmissão, direção, } \\
\text { eixos e reversores } \\
\text { marítimos }\end{array}$ \\
\hline $\begin{array}{l}\mathrm{N}^{\circ} \text { de unidades } \\
\text { industriais }\end{array}$ & 1 (Brasil) & 6 (Brasil) & $\begin{array}{c}3 \text { (Brasil), } 1 \\
\text { (Argentina), } 5 \\
\text { (Europa) e } 1 \text { (EUA) }\end{array}$ & $\begin{array}{c}\text { América Latina } \\
\text { (4 (Brasil) e } 1 \\
\text { (Argentina) }\end{array}$ \\
\hline Principais clientes & $\begin{array}{l}\text { Dana, ZF, Delphi, } \\
\text { GM, Honda, VW, } \\
\text { Maxion }\end{array}$ & $\begin{array}{c}\text { GM, FIAT, Honda, } \\
\text { VW, Toyota }\end{array}$ & $\begin{array}{c}\text { GM, VW, FORD, } \\
\text { FIAT, Daimler } \\
\text { Chrysler }\end{array}$ & $\begin{array}{c}\text { Europa, EUA e Ásia } \\
\text { Massey Fergusson, } \\
\text { Eaton, Case }\end{array}$ \\
\hline
\end{tabular}

Notas: ${ }^{1}$ A descrição da empresa Ômega está focada em suas atividades na América Latina. ${ }^{2} \mathrm{O}$ Brasil é o centro mundial de desenvolvimento de sistemas de eixos para tratores.

A Alfa tem mais de 50 anos de atuação no mercado brasileiro. Atualmente, atende a 3 montadoras e a fornecedores de primeiro nível. O início das operações concentrou-se no fornecimento de irrigadores ao setor agrícola e, logo após, no final da década de 1970, passou a atender o mercado automotivo (este representa, atualmente, $90 \%$ do faturamento). Possui instalações próprias e vem se adaptando para atender todas as exigências de seus clientes (montadoras e fornecedores de primeiro nível) quanto às demandas tecnológicas, de qualidade de produto e de saúde financeira, para garantir a continuidade no fornecimento futuro. Dedica-se exclusivamente à produção de peças avulsas e conjuntos estampados (módulos) utilizados na montagem de sistemas para automóveis e motocicletas, tais como: bancos e cintos, sistemas de freio, motores, portas, combustível, suspensão, câmbio e exaustão. Ao longo da década de 2000, internalizou diversas etapas de seu processo produtivo, antes realizadas pelos seus fornecedores. Em razão da tendência dos fornecedores de primeiro nível (aqueles em desenvolvimento e maduros) em aumentar a produção de subsistemas e sistemas modulares, a Alfa tem incorporado em sua linha mais produtos de concepção modular (conjuntos). No caso deste trabalho, a unidade de análise considerada é toda a linha de produtos da Alfa: peças e conjuntos.

A empresa Beta tornou-se recentemente uma multinacional brasileira e, durante sua trajetória, apresentou uma evolução em suas atividades. Do total dos funcionários da empresa, 40 estão alocados na área de engenharia de produto e 150 na área de engenharia de processo. No início de suas operações, a Beta dedicava-se às atividades de ferramentaria, utilizando processos de conformação a quente e a frio com atividades de usinagem de componentes ferrosos e não ferrosos para o setor automotivo. Posteriormente, adquiriu controle acionário de uma empresa fabricante de juntas automotivas, o que possibilitou seu ingresso no setor de pequenos e médios estampados, e na confecção de peças em borracha, metal-borracha e plásticos, passando também a desenvolver componentes para a indústria de motos e motociclos. O passo seguinte foi o início do desenvolvimento da linha de produção de subsistemas - colunas de direção e comandos de câmbio. Atualmente, a empresa tem cinco unidades industriais de componentes que integram sua linha de subsistemas e peças de grande porte, além de outra em fase de construção em Gravataí-RS para, inicialmente, atender a planta da GM. A Beta classifica sua linha de produtos como: peças usinadas/soldadas e de conjuntos soldados (destinados a componentes internos ou externos para caixas de mudança e motores, além de pontas de eixo) e produtos montados - subsistemas (modulares) - destinados a sistemas de transmissão e direção. No caso deste trabalho, a unidade de análise da Beta considerada são os módulos (subsistemas) destinados aos sistemas de transmissão e direção.

No início da sua trajetória, a empresa Gama se caracterizou por atividades de produção de componentes avulsos, tais como retentores de vedação dinâmicos utilizados em motores, transmissões e 
eixos; logo em seguida, ampliou sua oferta desta linha de produtos para os de vedação estática, denominados de juntas, além de mangueiras, denominadas de elementos de condução. Atualmente, a Gama possui uma posição de liderança global na oferta de peças avulsas (mangueiras de borracha e juntas de cabeçote) e subsistemas de vedação e condução de fluidos direcionados às montadoras. A empresa está caracterizada como fornecedora em fase de consolidação no primeiro nível da cadeia de suprimentos automotiva. Na Europa, tem uma posição consolidada como fornecedora das montadoras de automóveis e está expandindo sua presença no mercado americano com o início de suas operações produtivas locais, a partir de 2007. A empresa também está priorizando o desenvolvimento de novos negócios e produtos para as OEM's junto aos mercados americano e japonês. No caso deste trabalho, a unidade de análise considerada é toda a linha de produtos da Gama: peças e módulos (subsistemas de vedação e condução de fluidos).

A empresa Ômega é uma das líderes mundiais no fornecimento de sistemas de transmissão e tecnologia de chassis para o setor automotivo, o que lhe confere uma posição de fornecedora de primeiro nível na cadeia de suprimentos automotiva. A empresa conta com uma estrutura descentralizada para o PDP, localizada nos continentes europeu, americano (EUA e Brasil) e asiático. Cada unidade de negócio no mundo é responsável pelo desenvolvimento de um tipo de tecnologia e por todas as fases do PDP, incluindo análises técnicas de mercado, desenvolvimento do conceito, simulação de sistemas e componentes, design e simulações de engenharia, construção e testes de protótipo, até a fase de aprovação final. No Brasil, a Ômega oferece uma linha de produtos estruturada em duas divisões principais: i) powertrain e componentes de suspensão e ii) transmissões e eixos. Estas divisões atendem toda a América Latina (mercado de reposição), que conta com uma rede de mais de 150 concessionários da sua marca e venda direta às montadoras, e setor agrícola. $\mathrm{Na}$ América Latina, a Ômega fabrica transmissões para veículos comerciais, sistemas de direção, sistemas de embreagens, amortecedores e componentes de chassis para veículos comerciais e de passeio, além de eixos e transmissões para máquinas agrícolas e reversores marítimos. No caso deste trabalho, a unidade de análise da Ômega é de transmissões e eixos que são oferecidos na forma de sistemas modulares, tais como: transmissões manuais para veículos comerciais, transmissões automáticas para ônibus, eixos de tração para tratores agrícolas, e transmissões para tratores agrícolas e colheitadeiras.

\section{Apresentação e análise dos resultados}

Os resultados são apresentados segundo a lógica descrita anteriormente, iniciando pela identificação das competências modulares e das atividades de desenvolvimento de produto, seguindo para a análise individual e a análise cruzada dos casos.

\subsection{Identificação das competências modulares}

Na Tabela 1, encontram-se as competências modulares identificadas com base nos dados de campo. As mesmas estão descritas conforme a tipologia de progressividade de competências modulares proposta por Doran (2004) - Quadro 1. Estas competências foram extraídas da literatura (Tópico 3).

\subsection{Identificação das atividades de desenvolvimento de produto}

No Quadro 4, encontram-se as atividades de PDP identificadas com base nos dados de campo. As mesmas estão descritas conforme o Quadro 3.

\subsection{Análise individual dos casos}

Mediante a identificação das competências modulares (Tabela 1) e das atividades de PDP (Quadro 4), segue-se a análise individual dos casos com base nas competências identificadas e na literatura.

\section{A) Empresa Alfa}

De acordo com as competências identificadas, a empresa Alfa se encontra no estágio "embrionário" de progressividade de competências modulares, conforme a proposta de Doran (2004). A empresa inicia uma curva ascendente de agregação de novas capacitações tecnológicas, que pode ser evidenciada pela internalização de suas operações por meio de apoio financeiro de alguns de seus clientes, o que colaborou para um avanço no sentido da produção modular. Aliando as suas competências na oferta de tecnologia de corte fino de precisão fineblanking com estas novas competências operacionais, a Alfa está conquistando novas oportunidades neste ambiente modular. Segundo a análise dos critérios de seleção de fornecedores proposto por Svensson (2004) - que consideram o grau de comprometimento (intensidade de relacionamento) do fornecedor e de contribuição para a comoditização dos produtos de seus clientes -, a Alfa está se qualificando para realizar a transição em sua manufatura exclusiva de peças avulsas (tipo 
Quadro 4. Descrição dos determinantes de competências modulares das unidades de análise

\section{Recursos-chave}

A Alfa possui uma tecnologia de corte fino de precisão fineblanking (considerada como um diferencial competitivo no mercado automotivo), a linha de seus produtos compõe o produto de marca de seus clientes (não tem marca própria), possui um canal de vendas direto e está iniciando uma ampliação de conjuntos de concepção modular. A Beta realiza investimentos anuais na ordem de 1 a $2 \%$ sobre o faturamento que contempla P\&D e as unidades fabris, possui estrutura própria de engenharia de $\mathrm{P} \& \mathrm{D}$, atua no canal de vendas diretas e está iniciando o desenvolvimento do after market, vem desenvolvendo sua marca e ampliando linha de produtos de concepção modular, e participando de projetos de co-design diretamente com as montadoras e sistemistas (principalmente desenvolvimento de produtos tropicalizados, como a sua linha de comando de direção). A Gama realiza investimentos anuais, ao redor de $2 \%$ sobre o faturamento, recentemente unificou os centros de P\&D - Brasil e Alemanha - e também criou uma diretoria de compras globais, possui canais de vendas diretas e tem posição consolidada no after market (América Latina e Europa), está consolidando sua marca em âmbito global, possui uma ampla linha de produtos de reposição e tem capacidade de desenvolver produtos sob encomenda. A Gama, recentemente, explicitou em sua estratégia o objetivo de ampliar a oferta de produtos de concepção modular e vem participando de projetos em sistema de co-design diretamente com as montadoras e sistemistas. No Brasil, a Ômega tem sua diretoria geral de engenharia de P\&D responsável por 3 tecnologias principais: transmissões, eixos e reversores marítimos. A empresa utiliza os canais de vendas diretas e after market (possui uma rede de mais de 150 concessionários), além de ter uma marca global com oferta completa.

\section{Estrutura para o fornecimento de produtos e serviços}

Alfa internalizou as operações de soldagem, rebitagem e pintura por meio da cooperação financeira de seus clientes. Possui uma única planta de média capacidade. A Beta verticalizou suas operações pela compra de empresas ou transferência tecnológica, como, por exemplo: atividades de estamparia, componentes em borracha, metal-borracha e plásticos, e uma linha de produção de colunas de direção para oferecer conjuntos completos de comandos externos de câmbio e colunas de direção a produção de cabos de conduítes. Iniciou um processo de internacionalização e ampliação da capacidade de gestão do segundo nível. A Gama internalizou boa parte da produção e desenvolvimento de seus componentes e conta com fornecedores estratégicos de aço e borrachas técnicas que detêm grande capacidade de produção e tecnologia. Além disso, tem capacidade de gestão dos fornecedores do segundo nível. A Ômega, que é fabricante de sistemas modulares, detém o domínio da arquitetura do projeto e externaliza ou internaliza atividades de PDP (co-design com seus parceiros) ou produção ao segundo nível, conforme análises de custo e benefício (Item. 2.1.2). Alguns destes subsistemas, utilizados na fabricação de eixos, são: cilindros de direção, redução planetária, carcaças e diferencial. Cabe ressaltar que a Alfa, posicionada no segundo nível da cadeia de suprimentos e que, na maioria das vezes, realiza projetos de propriedade dos clientes, é fornecedora da Ômega que, por sua vez, exerce controle detalhado das especificações.

\section{Estrutura para o fornecimento de produtos e serviços}

As empresas pesquisadas (Alfa, Beta e Gama e Ômega) atendem os requisitos básicos de qualidade ISO 9001:2000, QS9000 e ISO TS 16949. Entre estas empresas, o requisito de qualidade assegurada somente não é atendido pela Alfa, que recebe auditoria de terceira parte pelos seus clientes em seu processo produtivo. Mediante esta condição, a Alfa tem pouca margem de negociação na definição de novos contratos de fornecimento. A empresa Beta e Gama estão conquistando novos contratos de fornecimento com maior grau de responsabilidade e risco, grande parte deles em sistema de co-design (grey-box), e a grande maioria de seus clientes (montadoras) recebem seus produtos diretamente em suas linhas de montagem. No caso da Ômega, todos seus contratos, tanto com as montadoras (codesign - grey box e black box) como com seus fornecedores (subsistemistas) são estabelecidos mediante cláusula de risco, além da entrega ser feita diretamente nas plantas.

\section{Relacionamentos interorganizacionais}

As empresas pesquisadas (Alfa, Beta e Gama e Ômega) atendem os requisitos básicos de qualidade ISO 9001:2000, QS9000 e ISO TS 16949. Entre estas empresas, o requisito de qualidade assegurada somente não é atendido pela Alfa, que recebe auditoria de $3^{\text {a }}$ terceira parte pelos seus clientes em seu processo produtivo. Mediante esta condição, a Alfa tem pouca margem de negociação na definição de novos contratos de fornecimento. A empresa Beta e Gama estão conquistando novos contratos de fornecimento com maior grau de responsabilidade e risco, grande parte deles em sistema de co-design (grey-box), e a grande maioria de seus clientes (montadoras) recebem seus produtos diretamente em suas linhas de montagem. No caso da Ômega, todos seus contratos, tanto com as montadoras (codesign - grey box e black box) como com seus fornecedores (subsistemistas) são estabelecidos mediante cláusula de risco, além da entrega ser feita diretamente nas plantas. 
Quadro 4. Continuação...

\section{Operações produtivas}

A Alfa possui operações de média capacidade, tendo maior parte de suas atividades com foco no setor automotivo e pouca flexibilidade operacional. A capacidade nas operações produtivas da Beta, Gama e Ômega, por ordem crescente, é considerada elevada. Tal fato é evidenciado pelo início de um processo de internacionalização das operações produtivas (Beta), a existência de processo de consolidação da estratégia de globalização e recente estruturação da engenharia de projetos para os mercados brasileiros e externos (Gama), e presença global consolidada e estrutura descentralizada de P\&D entre suas unidades de negócio da Europa, América e Ásia (Ômega). As empresas Beta, Gama e Ômega possuem flexibilidade operacional para atender montadoras com plantas de concepção de CI ou CM (Item 2.1).

\section{Posicionamento estratégico}

A Alfa é um agente reativo (cliente detém a propriedade do projeto e realiza controle detalhado das especificações) frente às tendências de adoção da modularidade, mas vem adquirindo capacidades modulares por imposição de seus clientes. Beta, Gama e Ômega são agentes pró-ativos (participação em projetos grey box ou black box) e se posicionam para ampliar suas operações de manufatura e PDP com foco na concepção modular.

\section{Diferenciais competitivos}

Considerando-se o ambiente de progressividade modular, a Alfa não possui fatores considerados como ganhadores de pedido. Este fato é confirmado pela limitação atual de criação de valor em um sistema modular de produção, mas vem desenvolvendo esforços nesta direção. Não possui fatores considerados como ganhadores de pedido. A Beta tem forte presença no mercado local, está iniciando um processo de internacionalização, vem desenvolvendo habilidades para atender condomínio industrial e consórcio modular com soluções modulares (co-design), está realizando investimentos crescentes em P\&D e tem capacidade de gestão do segundo nível. A Gama tem presença global em fase de consolidação, habilidades crescentes para atender condomínio industrial e consórcio modular com soluções modulares (co-design), tem capacidades de gestão do segundo nível em âmbito global, possui linha de produtos de marca e realiza investimentos crescentes em P\&D. A Ômega tem uma presença global consolidada, habilidades para atender condomínio industrial e consórcio modular com soluções modulares (co-design), competências consolidadas em $\mathrm{P} \& \mathrm{D}$, gerencia o segundo nível de alta tecnologia em âmbito global, além de ter uma linha de produtos de marca.

\section{Resultado: Potencial de transferência de atividades/know how}

As potencialidades de transferência de atividades podem ser consideradas proporcionais às competências modulares identificadas nas empresas pesquisadas. Tais competências definem o grau de envolvimento nos projetos da arquitetura do produto (automóvel) das montadoras. Está em curso uma configuração de troca de experiências e competências nos PDP entre os integrantes da cadeia de suprimentos (a transferência beneficia ambas as partes). Entre as empresas pesquisadas, a Ômega tem o maior potencial de transferência de atividades de acordo com sua grande autonomia para o desenvolvimento tecnológico de soluções modulares e pela sua flexibilidade operacional para internalizar ou transferir atividades a seus fornecedores de subsistemas. A Beta e a Gama também possuem alto potencial de transferência de acordo com sua autonomia tecnológica para o desenvolvimento de soluções modulares, mas de menor complexidade em relação aos sistemas da Ômega. As possibilidades de transferência de atividades para a Alfa são consideradas limitadas de acordo com sua autonomia de desenvolvimento de produtos de conteúdo tecnológico modular

commodity) para conjuntos de peças de concepção modular, bem como começa a alavancar sua área de desenvolvimento de novos produtos. Exemplos de fornecimento destas soluções modulares são os batentes, dobradiças e componentes para fechaduras e limitadores de portas desenvolvidos para a Honda. Neste caso, a Alfa teve a oportunidade de participar dos processos de desenvolvimento e definição das especificações e do projeto do processo de produção.

Conforme a análise de competências modulares (DORAN, 2004), a Alfa é um ator que está saindo de uma atitude reativa frente às mudanças no cenário automotivo, sem visão de longo prazo sobre o impacto da modularidade, e começa desenvolver conjuntos modulares que estão propiciando maior agregação de valor a seus negócios e viabilidade de parcerias mais duradouras com seus clientes.

\section{B) Empresa Beta}

De acordo com a tipologia de progressividade de competências (DORAN, 2004), a empresa Beta se encontra no estágio de "desenvolvimento" de progressividade de competências modulares. Tal fato pode ser evidenciado pelos seguintes fatores: 
Quadro 5. Envolvimento nas principais atividades de PDP das unidades de análise.

\section{Definições da estratégia do produto}

A limitada capacidade tecnológica da Alfa não lhe permite cooperar na avaliação do desenvolvimento tecnológico do produto e nas estratégias de PDP. A Beta tem conquistado novas oportunidades por meio da sua participação em projetos de tropicalização de componentes de montadoras, como: Honda, Peugeot, Renault, entre outras, o que caracteriza seu papel de follow sourcing, bem como está progressivamente participando de projetos em co-design. A Gama, por meio da implementação de sua estratégia de PDP modulares globais (linha de vedação e condução) está começando a exercer um papel de leader sourcing. As evidências de seu novo papel de leader sourcing são verificadas pela ampliação de sua participação no PDP em sistema de co-design - desde a idealização do projeto de um motor ou de uma transmissão. A Ômega, por meio de sua estratégia global de produtos de arquitetura modular e de projetos em sistema de co-design com fornecedores de alta tecnologia, caracteriza seu papel de leader sourcing. Outro aspecto relevante é a decisão da Ômega pela internalização de know how de seus processos de fundição e forja, mas que podem ser externalizados e controlados de acordo com as oportunidades de redução de custos.

\section{Desenvolvimento e definição das especificações}

A Alfa praticamente não tem influência na definição das especificações e recebe o desenho das peças do cliente previamente definido. A Alfa e seus clientes avaliam e testam componentes durante o processo de transformação. A Beta vem participando de projetos com a GM do tipo grey box. No caso dos projetos de desenvolvimento de comandos de câmbio para a GM, os detalhes sobre a adequação da funcionalidade são compartilhados, mas no caso da tecnologia empregada, isto não acontece. Estes projetos definem o auxílio na realização de testes no campo de provas da GM. A Gama está ampliando suas oportunidades no PDP do tipo grey box e nas suas participações em projetos em sistema de co-design. As especificações são desenvolvidas e compartilhadas quanto às interfaces dos subsistemas de vedação e condução estabelecidas com o veículo. A Gama tem autonomia para definir as especificações das MP entregues pelos fornecedores e realiza todos os testes dos módulos e seus subsistemas. A Ômega, na maioria das vezes, desenvolve produtos do tipo grey box e black box, define e compartilha as especificações quanto às interfaces com o veículo / trator e detém a patente do desenvolvimento de suas soluções modulares. A Ômega também realiza testes completos de seus módulos antes da sua montagem na planta do cliente.

\section{Preparação da produção e serviços ao cliente}

A Alfa tem tido oportunidades de cooperação com os testes de manufatura e embalagens e, principalmente, se dedica às atividades de produção para fornecedores de primeiro nível e montadoras. Beta, Gama e Ômega participam na maioria dos projetos e testes de manufatura e de embalagem, além de produzirem as peças (submódulos e módulos) com autonomia que depende do tipo de projeto da montadora.

i) os fornecedores estratégicos devem participar de processos de integração logística, just in time e PDP das montadoras para se integrarem na cadeia modular, de acordo com Collins, Bechler e Pires (1997); a Beta está investindo na construção de plantas industriais para atender tanto os sistemistas de condomínio como de consórcio modular; ii) com a mudança do papel das montadoras de integradoras para moduladoras das atividades de PDP (abordado por STURGEON, 2002), a Beta optou por internalizar operações produtivas anteriormente desenvolvidas por seus fornecedores de segundo e terceiro níveis, e pela aquisição de empresas, conforme demonstra a sua crescente agregação de valor na sua linha de produtos.

De acordo com Baldwin e Clark (1997) e Hoek e Weken (1998), estas são algumas das atividades não estratégicas para os negócios das montadoras e, portanto, passíveis de terceirização. A agregação destas atividades tem possibilitado um maior estreitamento de seu relacionamento com as montadoras, por meio de seu crescente envolvimento em projetos de concepção modular do tipo grey box (notadamente projetos de "tropicalização") destinados a algumas montadoras recentemente instaladas no país - Honda, Peugeot e Renault - e da padronização dos comandos de câmbio e colunas de direção a todas as plataformas de produção da GM. Estas evidências vão ao encontro da literatura (CLARK; FUJIMOTO, 1991; MONCZKA, 2000).

A Beta é um agente importante neste ambiente modular, pois tem foco bem definido sobre fatoreschave de mudança nas atividades de PDP que estão ocorrendo no setor automotivo. As intenções da Beta são, em um primeiro momento, se consolidar no mercado brasileiro como fornecedora estratégica modular com o fornecimento de subsistemas e componentes de grande porte avulsos usinados e estampados para, em um período de médio a longo prazo, expandir suas atividades nos continentes europeu e americano. 


\section{C) Empresa Gama}

A empresa Gama, ao longo dos anos, vem adotando uma estratégia de foco no desenvolvimento e na produção de componentes avulsos (retentores de vedação - juntas e mangueiras - elementos de condução), considerados críticos para o desenvolvimento de motores, transmissões e eixos. Em um primeiro momento, a Gama conquistou a liderança no fornecimento destes produtos às montadoras instaladas no Brasil e já desfruta de uma posição estratégica em âmbito global. Estas estratégias adotadas pela Gama lhe conferem um posicionamento intermediário entre os estágios de "desenvolvimento" e "maturidade" na progressividade de competências modulares (DORAN, 2004).

As oportunidades de negócios da Gama podem ser classificadas em duas frentes distintas: mercados interno e externo. Quanto ao mercado interno, a grande maioria dos projetos da Gama são de otimização e de novas aplicações com base em projetos pré-existentes das montadoras em que desempenha um papel de follow sourcing; nestes casos, os projetos são de baixa atratividade, pois existe grande pressão das montadoras para a redução de custos e a melhoria da qualidade sem a contrapartida dos investimentos realizados. Em alguns casos, tem obtido êxito na participação em desenvolvimento de produto de tecnologias locais - motor flex, bicombustível e veículos, como o modelo Fox da Volkswagen. Outras oportunidades são de tropicalização de produtos direcionados às necessidades das montadoras instaladas mais recentemente no Brasil, como nos casos da Toyota, Honda, Peugeot e Renault.

Quanto ao mercado externo, é a participação nos projetos desde o nascimento do conceito de um motor, transmissão ou eixo, que lhe dá a oportunidade de desempenhar um papel de leader sourcing. Um exemplo é o desenvolvimento de componentes modulares e não modulares que são utilizados em uma transmissão da GM. Embora tais projetos não sejam considerados de grande complexidade, estes permitem grande envolvimento (contrato de longo prazo). Tais componentes começarão a ser produzidos em 2012, mas seus mock-ups foram encomendados a partir de janeiro de 2007. Conforme abordado anteriormente por Clark e Fujomoto (1991) e Monczka (2000), estas oportunidades caracterizam a evolução da Gama nas capacidades tecnológicas necessárias na direção do desenvolvimento de subsistemas na forma de grey box e black box.

Alguns dos principais aspectos em que a estratégia de globalização adotada pela Gama se baseia estão respaldados pela literatura. Sanchez e Mahoney (1996) e Sturgeon (2002) apontam que a evolução da Gama como fornecedora global implica em mudanças na sua arquitetura organizacional e na gestão de sua cadeia de suprimentos. Algumas destas evidências verificadas são: i) a internalização do desenvolvimento de componentes considerados de menor valor agregado; ii) início de um processo de implementação de planejamento para o desenvolvimento de uma linha de produtos modulares em sistemas de vedação e condução que visam atender projetos globais das montadoras; iii) consolidação e unificação de sua estrutura global de P\&D e compras, ou seja, uma mudança em sua arquitetura organizacional; e iv) início de operações produtivas nos Estados Unidos, após sua consolidação nos mercados da América Latina e Europa e, em breve, abertura de escritório de representação no Japão.

\section{D) Empresa Ômega}

Os principais diferenciais competitivos da Ômega são a presença global, os investimentos significativos e a estrutura descentralizada em $P \& D$, a posição competitiva como líder global no desenvolvimento e na produção de sistemas modulares de transmissões e eixos para tratores, as competências bem desenvolvidas em PDP modulares, o gerenciamento do segundo nível de empresas de alta tecnologia e uma linha de produtos de marca.

A Ômega tem autonomia para liderar PDP junto às montadoras e flexibilidade para optar pela internalização ou terceirização de atividades de manufatura e desenvolvimento de subsistemas ou componentes. Portanto, a Ômega se encontra no estágio de "maturidade" de competências modulares (DORAN, 2004). Desde a década de 1980, adota a estratégia global de PDP de conceito modular e como apoio utiliza a literatura de Ulrich e Eppinger (1995), além de acervo técnico próprio. Entre os fornecedores da Ômega, destacam-se os de freios (TRW e Bosch) e cilindros hidráulicos de direção (Unideme, KMS-Weber e Parker). Estes fornecedores detêm capacidade tecnológica para o desenvolvimento de produto na forma de grey box e black box em sistema de co-design. A Ômega detém o know how de alguns destes subsistemas, o que possibilita uma estratégia de flexibilização de suas operações. O cilindro de direção é um destes casos em que a empresa prefere terceirizar seu desenvolvimento e produção, mas pode retomar a sua produção de acordo com as oportunidades de mercado e necessidades de redução nos custos.

O fato de a Ômega conduzir o desenvolvimento de produtos modulares e transferir a responsabilidade da gestão da qualidade e custo destes módulos a seus fornecedores é benéfico, resultando em ganhos importantes, tais como: menor tempo no desenvolvimento de novos produtos e simplificação do processo de montagem em sua linha de produção; eliminação das atividades de produção de componentes relacionados a estes subsistemas; centralização dos 
esforços no desenvolvimento das suas competências centrais (engrenagem e tração).

\subsection{Análise cruzada dos casos}

A seção anterior (5.2) permitiu classificar as empresas de acordo com o estágio de maturidade de competências modulares, com base nas unidades de análise, sendo a empresa Alfa (embrionária), a empresa Beta (em desenvolvimento), a empresa Gama (entre o estágio de desenvolvimento e maturidade) e a empresa Ômega (madura).

Dentre as competências levantadas, a Figura 2 ilustra quais são os diferenciais competitivos identificados nas empresas quanto à presença global, às competências em $\mathrm{P} \& \mathrm{D}$ com enfoque em soluções modulares, ao gerenciamento do segundo nível da cadeia de suprimentos, além de contar com uma linha de produtos de marca. Uma análise do posicionamento de cada uma das empresas frente aos diferenciais competitivos foi realizada a fim de viabilizar a análise comparativa do grau de maturidade modular obtido pelos fornecedores. Em um segundo momento, este perfil também serve de base para avaliar a relação entre as competências identificadas e o grau de envolvimento nas práticas de DP.

A Ômega, em relação às demais empresas, tem o melhor desempenho em todos os diferenciais competitivos analisados. Mediante o contexto modular, estes diferenciais garantem à empresa a capacidade de criar maior valor às montadoras e a seus negócios. De acordo com o modelo de segmentação e critérios para seleção de fornecedores proposto por Svensson (2004), confirma-se que a Ômega tem maior grau do comprometimento e de contribuição para a "customização" dos produtos de seus clientes por meio da oferta de sistemas modulares e de serviços completos de montagem direta na planta.
A empresa Gama está próxima de atingir o estágio de maturidade modular, o que depende de investimentos em P\&D com enfoque em soluções modulares. Conforme Clark e Fujimoto (1991) e Monczka (2000) indicam, a empresa entende que o diferencial competitivo no desenvolvimento de produtos modulares pode garantir acesso a novas oportunidades de projetos considerados de grande atratividade (co-design).

A empresa Beta, por sua vez, em comparação com os diferenciais competitivos da Gama, apresenta menor penetração nos mercados internacionais e se restringe à gestão da cadeia de segundo nível e desenvolvimento de marca própria ao mercado brasileiro. Por sua vez, tem um posicionamento em suas competências com maior foco em P\&D e projetos de concepção modular.

A empresa Alfa tem tido a oportunidade de acumular competências modulares, ainda de forma embrionária. Com base na argumentação de Figueiredo (2003), tal posicionamento restringe a sua capacidade tecnológica às operações rotineiras de produção de peças sob encomenda.

Após a análise comparativa de posicionamento das empresas frente aos diferenciais competitivos (Figura 2), é analisado o grau de envolvimento das empresas nas principais práticas de desenvolvimento de produto. A Figura 3 mostra o posicionamento relativo do envolvimento das empresas nas práticas de desenvolvimento de produto e de manufatura com base no referencial teórico apresentado no Quadro 3. Tais práticas foram divididas em 3 categorias: i) as práticas decorrentes da participação dos fornecedores nos estágios iniciais de definições da estratégia do produto; ii) o envolvimento com o desenvolvimento, e iii) a definição das especificações e o desenvolvimento com a preparação da produção e de serviços ao cliente.

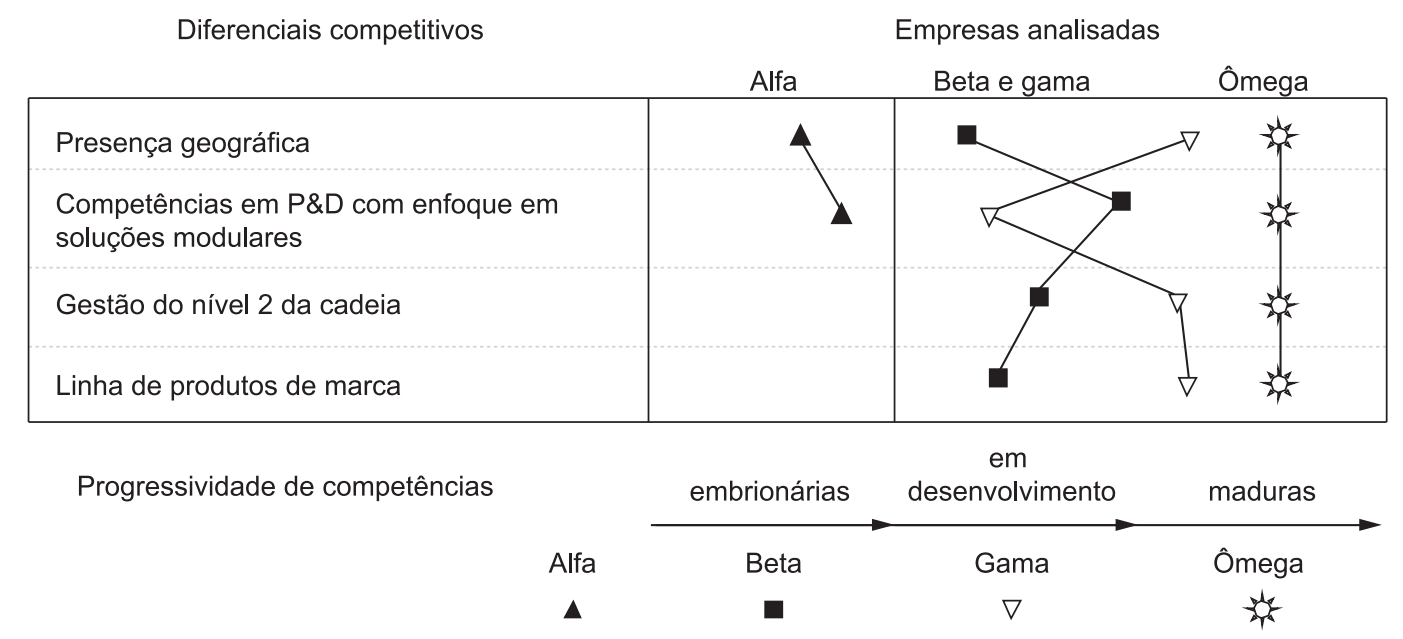

Figura 2. Análise comparativa de posicionamento das empresas frente aos diferenciais competitivos. 
Principais categorias de práticas de DP

Posicionamento das empresas

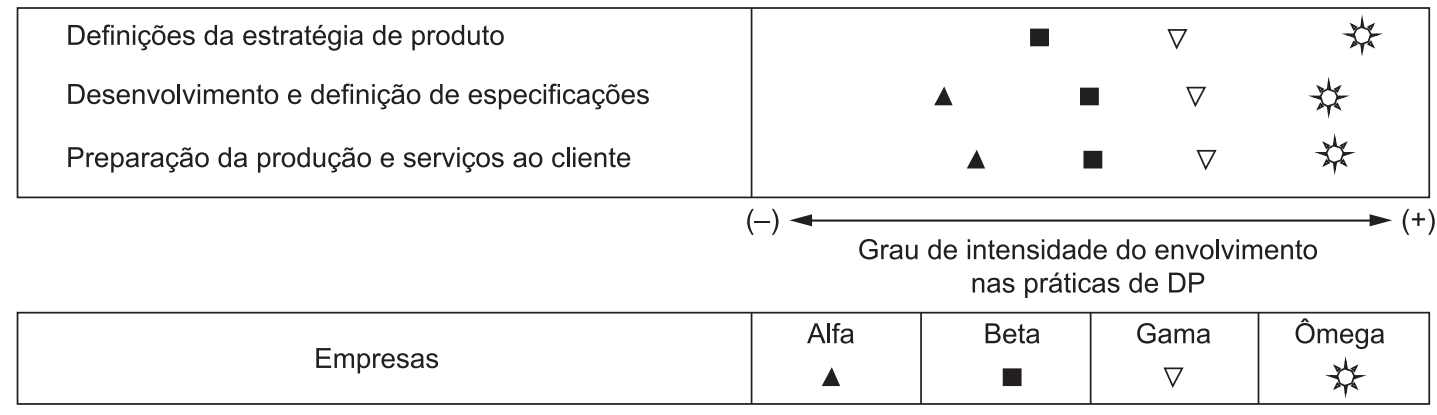

Figura 3. Grau de envolvimento nas práticas de desenvolvimento de produto.

A síntese teórica mostrada no Quadro 3 apontou que a maior intensidade de envolvimento entre os fornecedores e clientes da cadeia automotiva nas atividades de desenvolvimento de produto é estabelecida mediante parcerias de risco nos investimentos, parcerias em tecnologias e parcerias em projetos de co-design. As atividades de menor envolvimento entre os fornecedores e clientes são caracterizadas pelo fornecimento de serviços de engenharia e manutenção, e de componentes padrão. O maior envolvimento entre os integrantes da cadeia pode determinar contratos de fornecimento de longo prazo. Portanto, as evidências coletadas nas empresas analisadas puderam posicioná-las em níveis distintos de maturidade modular e de envolvimento nas práticas de DP. Pela ordem, as empresas que têm maior envolvimento nas práticas de DP são: Ômega, Gama, Beta e Alfa. Quanto à Alfa, ainda não tem oportunidade de participação nas atividades-chave do DP.

\section{Conclusões}

Este estudo investigou os determinantes da EM no processo de capacitação e na transferência de atividades de desenvolvimento de produto entre os fornecedores de nível 1 e 2 da cadeia de suprimentos automotiva. $\mathrm{O}$ estudo se propôs a identificar quais são os determinantes de competências e as práticas de desenvolvimento de produto características do contexto modular potencialmente transferidos para os fornecedores e a sua relação com o grau de maturidade nas competências modulares. A tipologia de progressividade da literatura permitiu analisar e posicionar as empresas estudadas de acordo com o estágio de maturidade de competências modulares.

Pode-se concluir, com base nos dados de campo, que a empresa Alfa é "embrionária", a empresa Beta encontra-se "em desenvolvimento", a empresa Gama está entre o estágio de "desenvolvimento" e "maturidade" e a empresa Ômega já é "madura". As práticas de DP evidenciadas confirmaram o estágio de maturidade modular em cada organização estudada, considerando a particularidade da unidade de análise investigada. Neste sentido, confirma-se que as competências da SC devem ser desenvolvidas tendo-se como base a estratégia modular.

Em termos do grau de intensidade, o resultado foi diferenciado entre as empresas. Não obstantemente, todas as empresas analisadas têm a preocupação especial de internalizar atividades de PDP e de manufatura, investindo em P\&D para desenvolver uma proposição de valor superior a seus clientes e, por sua vez, um maior potencial de transferências de atividades. Esse foi um resultado esperado devido à natureza da competitividade na SC automotiva. Complementarmente, as evidências empíricas deste trabalho confirmaram que os projetos de desenvolvimento de produto de concepção modular possibilitam, em primeiro lugar, aos fornecedores de primeiro nível uma maior participação nas atividades estratégicas de desenvolvimento de produto e, aos fornecedores de segundo nível, uma maior participação nas atividades operacionais. $\mathrm{O}$ benefício para os integrantes da cadeia automotiva (montadoras e seus fornecedores diretos de primeiro e de segundo nível - caso do condomínio industrial) é o fornecimento de longo prazo, menores custos de produção e participação em desenvolvimento de produtos modulares, além de maior qualidade assegurada e estabilidade no fornecimento. Contudo, esses aspectos não foram analisados em profundidade e podem ser investigados em estudos futuros. Confirma-se, no entanto, que a estratégia modular impõe aos constituintes da cadeia de suprimentos automotiva (de primeiro e segundo nível), um processo progressivo de aquisição de competências e na consequente transferência de atividades de projeto das montadoras. Os dados apresentados neste trabalho permitem identificar o estágio de progressividade de competências modulares e a sua importância para a competitividade das empresas na cadeia de suprimentos automotiva. De acordo com a estratégia modular adotada pelas montadoras, e apontada na literatura, os fornecedores devem atingir a maturidade de competências modulares para permanecer competitivos em um contexto de parcerias globais. 


\section{Agradecimentos}

Os autores agradecem aos avaliadores do artigo que contribuíram significativamente para sua melhoria e também às empresas que permitiram que este estudo fosse realizado. Ressalte-se que o trabalho reflete a visão dos autores e não a das organizações investigadas. Um dos autores é professor colaborador do Programa de Pós-graduação em Engenharia de Produção da Escola Politécnica da USP e tem vínculo com a Universidade Federal de Santa Cataria e, por esta razão, esta instituição também merece agradecimentos. Os autores também agradecem ao $\mathrm{CNPq}$ pelo apoio ao desenvolvimento do presente trabalho (bolsa de mestrado e bolsa PQ).

\section{Referências}

BALDWIN, C. Y.; CLARK, K. B. Managing in the Ages of Modularity. Harvard Business Review, p. 84-93, 1997.

BECKER, M. C.; ZIRPOLI, F. Organizing New Product Development - Knowledge Hollowing-Out And Knowledge Integration - the FIAT Auto Case. International Journal of Operations and Production Management, v. 23, n. 9; p.1033-1061, 2003. http:// dx.doi.org/10.1108/01443570310491765

CALABRESE, G. Small-medium suppliers and the new car industry. International Journal of Automotive Technology and Management, v. 1, n. 4, p. 471-489, 2001. http://dx.doi.org/10.1504/IJATM.2001.000053

CAMUFFO, A. Rolling Out a World Car: Globalisation, Externalisation and Modularity in the Auto Industry. Vehicle: Department of Business Economics and Management Ca Foscari University of Vehicle, 2000. Disponível em: <http://www.imvp.mit.edu/papers/0001/ camuffo1.pdf>. Acesso em: 05 set. 2005

CLARK, K. B.; FUJIMOTO, T. Product development performance: strategy, organization and management in the world auto industry. Boston: Harvard Business School Press, 1991.

COLLINS, R., BECHLER, K.; PIRES, S. Outsourcing in the Automotive Industry: From Just in Time to Modular Consortia. European Management Journal, v. 15, n. 5, p. 498-508, 1997. http://dx.doi.org/10.1016/ S0263-2373(97)00030-3

CORSWANT, F.; FREDRIKSSON, P. Sourcing Trends in the Car Industry: A Survey of Car Manufacturers and Suppliers Strategies and Relations. International Journal of Operations and Production Management, v. 22, n. 7-8, p. 741-758, 2002. http://dx.doi. org/10.1108/01443570210433526

DORAN, D. Manufacturing for synchronous supply: a case study of Ikeda Hoover Ltd. Integrated Manufacturing Systems, v. 13, n. 1, pp. 18-24, 2002.

DORAN, D. Supply Chain Implications of Modularization. International Journal of Operations and Production Management, v. 23, n. 3, p. 316-326, 2003. http:// dx.doi.org/10.1108/01443570310462785

DORAN, D.; ROOME, R. An Evaluation of Value-Transfer within a Modular Supply Chain. International Strategy and Research Operations Group, v. 217, 2003. part D: J. Automobile Engineering.

DORAN, D. Rethinking the supply chain: an automotive perspective. Supply Chain Management: An International Journal, v. 9, n. 1, p. 102-109, 2004.

EISENHARDT, K. M. Product Development: Past Research: Present Findings and Future Directions. Academy of Management Journal, v. 32, n. 3, p. 543-579, 1989. http://dx.doi.org/10.2307/256434

FIGUEIREDO, P. S. Aprendizagem Tecnológica e Performance Competitiva. Rio de Janeiro: Editora FGV, 2003. 292 p.

FREDRIKSSON, P. Modular assembly in the car industry - an analysis of organizational forms' influence on performance. European Journal of Purchasing \& Supply Management, v. 8, p. 221-233, 2002. http:// dx.doi.org/10.1016/S0969-7012(02)00018-7

GRAZIADIO, T. Estudo Comparativo Entre os Fornecedores de Componentes Automotivos de Plantas Convencionais e Modulares. São Paulo. 2004. Tese (Doutorado em Engenharia)-Escola Politécnica, Universidade de São Paulo, São Paulo, 2004. http:// dx.doi.org/10.1504/IJATM.2003.003378

GRAZIADIO, T.; ZILBOVICIUS, M. Knowledge transfer through the supply chain does modularity make it easier? International Journal of Automotive Technology and Management, v. 3, n. 1-2, p. 47-60, 2003.

HANDFIELD, R. et al. Involving suppliers in new product development. California Management Review \& Fall, v. 42, n. 1, p. 59-82, 1999.

HENDERSON, R. M.; CLARK, K. B. Architectural Innovation: The Reconfiguration of Existing Product Technologies and the Failure of Established Firms. Administrative Science Quarterly, Mar, v. 35, n. 1, 1990.

HOEK, R. I. van; WEKEN, H. M. The Impact of Modular Production on the Dynamics of Supply Chains. International Journal of Logistics Management, v. 9, n. 2, p. 33-50, 1998.

HUANG, C. C. Overview of Modular Product Development. Proceedings National Science Council, v. 24, n. 3, p. 149-165, 2000.

HUMPHREY, J.; SCHMITZ, H. Governance and Upgrading: Linking Industrial Cluster and Global Value Chain Research. IDS Bulletin, v. 32, n. 3, 2001.

JÜRGENS, U. Restructuring of Supplier Relations within the Automotive Industry. Working Group - Knowledge, Production Systems and Work. Germanwatch: Misereor and the Publications Department of the Church Development Service, 2004.

MARTIN, M. V.; ISHII, K. Design for Variety: A Methodology for Developing Product Platform Architectures. In: ASME DESIGN ENGINEERING TECHNICAL CONFERENCE - DETC, Baltimore. Proceedings... Baltimore: ASTM, 2000. p. 1-15.

MONCZKA, R. M. et al. New product development: Strategies for supplier integration. Milwaukee: ASQ Quality Press, 2000. 209 p.

MORRIS, D.; DONELLY, T.; DONELLY, T. Insights from Industry: Supplier Parks in the Automotive Industry. Supply Chain Management: An International 
Journal, v. 9, n. 2, p. 129-133, 2004. http://dx.doi. org/10.1108/13598540410527024

NEPAL, B. P. An Integrated Framework for Modular Product Architecture. Michigan: Degree of Doctor of Philosophy, Graduate School of Wayne State University, 2005.

SALERNO, M. S.; CARNEIRO, A. V. D. Product design modularity, modular production, modular organization: the evolution of modular concepts. Actes du GERPISA, v. 33, p. 61-73, 2002.

SANCHEZ, R.; MAHONEY, J. T. Modularity, flexibility, and Knowledge management in product and organization design. Strategic Management Journal, v. 17, p. 63-76, 1996.

SANCHEZ, R. Using Modularity to Manage the Interactions of Technical and Industrial Design. Design Management Journal Academic Review, v. 2, p. 8-19, 2002. http:// dx.doi.org/10.1111/j.1948-7177.2002.tb00008.x

SHIMOKAWA, K. Reorganization of the Global Automobile Industry and Structural Change of the Automobile Component Industry. International
Motor Vehicle Programm, 2002. Disponível em: <http:// hdl.handle.net/1721.1/1417>.

STURGEON, T. J. Modular Production Metworks: A new American model of industrial organization. Industrial and Corporate Change, v. 11, n. 3, p. 451- 496, 2002. http://dx.doi.org/10.1093/icc/11.3.451

SVENSSON, G. Supplier segmentation in the automotive industry - A dyadic approach of a management model. International Journal of Phisical Distribution \& Logistics Management, v. 34, n. 1-2, p. 12-38, 2004. http://dx.doi.org/10.1108/09600030410515664

ULRICH, K.; EPPINGER, S. D. Product Design and Development. New York: McGraw-Hill, 1995.

ULRICH, K. The Role of Product Architecture in the Manufacturing Firm. Research Policy, v. 24, p. 419-440, 1995. http://dx.doi.org/10.1016/0048-7333(94)00775-3

YASSINE A.A.; WISSMANN L. A. The implications of product architecture on the firm. Systems Engineering, v. 10, n. 2, p. 118-137, 2007.

YIN, R. Estudo de caso: Planejamento e Métodos. Porto Alegre: Bookman, 2005. 